\title{
Prognostic implications of histological clear cells in high-grade intracranial ependymal tumors: A retrospective analysis from a tertiary care hospital in Pakistan
}

\author{
Fauzan Alam Hashmi \\ Aga Khan University, fauzan.alam@aku.edu \\ Hamid Hussain Rai \\ Aga Khan University \\ Muhammad Faheem Khan \\ Aga Khan University \\ Muhammad Ehsan Bari \\ Agha Khan University, ehsan.bari@aku.edu
}

Follow this and additional works at: https://ecommons.aku.edu/pakistan_fhs_mc_surg_neurosurg

Part of the Neurology Commons, Neurosurgery Commons, and the Surgery Commons

\section{Recommended Citation}

Hashmi, F. A., Rai, H., Khan, M., Bari, M. (2018). Prognostic implications of histological clear cells in highgrade intracranial ependymal tumors: A retrospective analysis from a tertiary care hospital in Pakistan. Asian Journal of Neurosurgery, 13(2), 307-313.

Available at: https://ecommons.aku.edu/pakistan_fhs_mc_surg_neurosurg/104 


\title{
Asian Journal of
Neurosurgery
}

Asian J Neurosurg. 2018 Apr-Jun; 13(2): 307-313.

PMCID: PMC5898097

doi: 10.4103/ajns.AJNS 28016

PMID: 29682026

\section{Prognostic Implications of Histological Clear Cells in High-Grade Intracranial Ependymal Tumors: A Retrospective Analysis from a Tertiary Care Hospital in Pakistan}

\author{
Fauzan Alam Hashmi, $\underline{\text { Hamid Hussain Rai, }}{ }^{1}$ Muhammad Faheem Khan, and Muhammad Ehsan Bari \\ Department of Surgery, Section of Neurosurgery, Aga Khan University Hospital, Karachi, Pakistan \\ ${ }^{1}$ Department of Surgery, Aga Khan University Hospital, Karachi, Pakistan \\ Address for correspondence: Dr. Muhammad Ehsan Bari, Department of Surgery, Section of Neurosurgery, Aga Khan University \\ Hospital, Stadium Road, P.O. Box 3500, Karachi 74800, Pakistan. E-mail: ehsan.bari@aku.edu
}

Coppyright : @ 2018 Asian Journal of Neurosurgery

This is an open access journal, and articles are distributed under the terms of the Creative Commons Attribution-NonCommercialShareAlike 4.0 License, which allows others to remix, tweak, and build upon the work non-commercially, as long as appropriate credit is given and the new creations are licensed under the identical terms.

Abstract Go to:

\section{Background:}

Clear cell variant in ependymal tumors is rare. We aimed to compare the features and outcome of the World Health Organization (WHO) Grade 3 ependymal tumors with clear cells to the WHO Grade 3 classic anaplastic ependymoma (AE).

\section{Materials and Methods:}

A retrospective cohort study conducted at the Department of Neurosurgery, Aga Khan University, Pakistan, from 2003 to 2013. The medical records and radiology of patients with proven histopathology were reviewed. The analysis was done on SPSS 20.

\section{Results:}

Nine cases of clear cell variant and 23 cases of classic AE were found, both of which combined equated to $4 \%$ of the total tumor burden in 11 years. The median age of clear cell ependymoma (CCE) and $\mathrm{AE}$ were 49 and 37 years, respectively. Presenting symptoms included headache in $66 \%$ of CCE and $63 \%$ in $\mathrm{AE}$, raised intracranial pressure accounting for $33 \%$ of CCE and $54 \%$ of AE, dizziness in $22 \%$ CCE and $39 \%$ AE, while seizures presented equally in both. Supratentorial location was observed in $77 \% \mathrm{CCE}$ and $48 \%$ AE. Both showed hypointense signals on T1-weighted images of magnetic resonance imaging (MRI) while T2-weighted images showed hyperintensity in all cases of CCE but only $80 \%$ of AE. MRI characteristics such as the presence of cystic component were found in $89 \%$ of $\mathrm{CCE}$ and $68 \%$ of $\mathrm{AE}$, necrosis in 33\% CCE, and $22 \% \mathrm{AE}$, hemorrhagic in $22 \% \mathrm{CCE}$ and $9 \% \mathrm{AE}$, and equivalent contrast enhancement. Gross total resection was achieved in $5(55 \%)$ patients of CCE, compared to $6(26 \%)$ patients in AE. Subtotal resection was done in $4(44 \%)$ patients of CCE and 15 (65\%) patients of AE. Radiotherapy was given to $5(55 \%)$ patients of CCE and $12(52 \%)$ patients of AE. Recurrence was observed in $77 \%$ cases of CCE and $70 \%$ of AE, with metastasis in $29 \%$ of AE and in only one patient of CCE. Repeat surgery was done in $3(33 \%)$ cases of CCE and $8(35 \%)$ cases of 
AE. Median progression-free survival and overall survival were 9 and 13 months, respectively, in CCE while 14 and 18 months, respectively, for AE.

\section{Conclusion:}

Clear cells in the WHO Grade 3 ependymal tumors are found mainly in a comparatively older adult population with a predilection for supratentorial location and are more aggressive in behavior with poorer outcome than AE.

Keywords: Anaplastic ependymoma, clear cell ependymoma, progression-free survival, recurrence, rosettes

Ependymal tumors are relatively rare glial tumors arising from ependymal cells in the brain which constitute only $2 \%-8 \%$ of the central nervous system (CNS) malignancies.[1] The revised World Health Organization (WHO) classification of brain tumors in 2007 broadly classified ependymomas into three histological grades. Myxopapillary ependymomas and subependymomas being classified as Grade 1 tumor. Clear cell, papillary, cellular, and tancytic subtypes considered as Grade 2 tumors. And the anaplastic variant being considered as a Grade 3 tumor.[2] In contrast to other glial tumors, the histological grade of ependymal tumors has conflicting significance as a prognostic and predictive marker.[3, 4$]$ In addition to the histological grade, the site of the tumor and the age at the initial diagnosis has been a pertinent prognostic factor for survival in patients with ependymomas.[్] In recent years, classification of ependymomas based on tumor location such as supratentorial ependymomas, posterior fossa ependymomas, and spinal ependymomas has highlighted an in-depth insight as one of the most important determinants of outcome.

Clear cell ependymoma (CCE) is a rare, diagnostically challenging and aggressive variant of ependymomas, with acceptance as a separate entity in the WHO classification of tumors only in 1993. [] Ever since it was first described in 1983,[7] the literature has been scarce on this entity. Although CCE is mostly supratentorial in location, other sites mentioned in the literature include cervical and thoracic spinal cord, brain surface, medulla, fourth ventricle, and cerebellum. $[\underline{8}, \underline{9}, \underline{10}, \underline{11}, \underline{12}, \underline{13}, \underline{14}, \underline{15}]$ Histologically, CCE tumor cells display classic ependymal rosettes and perivascular pseudorosettes with an oligodendroglioma (ODG) such as appearance having a clear perinuclear halo and positive immune reactivity to glial fibrillary acidic protein and epithelial membrane antigen. $[\underline{2}, \underline{10}, \underline{11}]$ In comparison, anaplastic ependymoma (AE) display increased cell density, brisk mitotic activity, microvascular proliferation, and palisading necrosis.[16] The similar gene expression patterns of Grade 2 and Grade 3 malignancies highlight progression of Grade 2 into Grade 3 ependymomas.

CCE although being a variant of Grade 2, ependymoma has most of the published series to date highlighting the presence of clear cells more in histologically proven AE Grade 3 than Grade 2.[14] The elusive histological criteria with no cutoffs being defined for mitosis or percentage of tumor depicting increased cellularity, grading of ependymoma into Grades 2 and 3 remains controversial, and unreliable in predicting the outcome.[16] Hence, it is important to distinguish this entity from other pathologies which may pose a diagnostic challenge, such as ODG, central neurocytoma, clear cell carcinoma, and hemangioblastoma, especially as the treatment and prognosis of each differ significantly. Surgery remains the mainstay treatment for ependymal tumor. It is desirable to attempt a gross total resection (GTR) where possible, without causing neurological deficits with concomitant radiotherapy, as postoperative radiotherapy improves survival. A clear advantage of augmenting radiotherapy with chemotherapy is yet to be established.

Therefore, we aimed to compare the frequency, clinical, radiological, surgical and histopathological aspects, with outcome such as progression-free survival (PFS) and overall survival (OS) of the WHO 
Grade 3 ependymal tumors with clear cells to the WHO Grade 3 classic AE.

This was a retrospective cohort study conducted at the Department of Neurosurgery, Aga Khan University Hospital, Karachi, Pakistan. Institutional approval was obtained from the Ethics Review Committee, and informed consent was acquired from the enrolled patients. Medical Records of all the cases of primary CNS tumors operated from January 2003 to December 2013 were retrieved and reviewed from the electronic database of the hospital using International Classification of Diseases codes 190.0-191.9.

Data were systematically collected on a structured pro forma, which included patient demographics, presenting complaints, Karnofsky Performance Score (KPS), radiology, course of treatment, including surgery, adjuvant therapy (radiotherapy [RXT] and chemotherapy [CMT]), PFS, and recurrence as suggested by interval 3 monthly magnetic resonance imaging (MRI) of the brain and OS.

Information about aforementioned aspects was obtained from patient's initial outpatient department notes, initial assessment forms, progress notes, operative notes retrieved through medical record office, and telephonic calls to patients/attendants where applicable. MRI of the brain was reviewed on picture archiving and communication system of the hospital for tumor location, initial size, and features specific to tumors such as contrast enhancement, appearance on T1- and T2-weighted images, and associated characteristics such as the presence of cystic, hemorrhagic, or necrotic areas were obtained. The histopathology slides were retrieved and reviewed by a single consultant histopathologist of all the cases showing Grade 3 ependymal tumors, including classic AE and the clear cell variant.

GTR was defined as excision of more than $95 \%$ of tumor, and subtotal resection (STR) was defined as excision of $<95 \%$ tumor.

Descriptive analysis was done using SPSS version 20 (IBM). Median was calculated for continuous variables, with frequencies and proportions being calculated for categorical variables. Survival analysis was done using log-rank test and Kaplan-Meier curves, with hazard ratio being calculated by logistic regression.

Results Go to:

For the eleven-year period starting January 2003 to December 2013, surgery was done on 677 cases of primary intracranial tumors at Aga Khan University Hospital. Seven percent of these cases constituted as ependymal tumors, of which 4\% were Grade 3 ependymal tumors, in which 23 cases were classic AE, whereas nine cases were Grade 3 ependymal tumors with clear cells.

The male-female ratio of CCE tumors was 6:3 whereas that of AE tumors was 10:13. The median age was 49 years for CCE and 37 years for AE. The age range for CCE was from 24 to 72 years while 3 months to 75 years for AE. Hence, a few pediatric cases reported in AE while none in CCE.

The majority of patients presented with headache as the most common complaint, with $66 \%$ in CCE and $63 \%$ in $\mathrm{AE}$, followed by features of raised intracranial pressure (ICP) - 54\% in AE as compared to $33 \%$ in CCE. Dizziness/vertigo was found more in AE with $39 \%$ as compared to $22 \%$ of CCE, with seizures overlapping in both groups. The presenting KPS was similar in the two groups. These results are summarized in Table 1. 
Prognostic Implications of Histological Clear Cells in High-Grade Intracranial Ependymal Tumors: A Retrospective Analysis from a Tertiar...

\begin{tabular}{lcc}
\hline & CCE & AE \\
\hline $\begin{array}{l}\text { Number of cases } \\
\text { Gender }(n)\end{array}$ & 9 & 23 \\
$\quad$ Male & 6 & 10 \\
Female & 3 & 13 \\
Age (years) & & \\
$\quad$ Median & 49 & 37 \\
Range & $24-72$ & $0.25-75$ \\
Symptoms (\%) & & \\
Headache & 66 & 63 \\
Raised ICP & 33 & 54 \\
Dizziness & 22 & 39 \\
Seizures & 22 & 22 \\
Karnofsky Performance Score (\%) & & \\
$\quad<70$ & 33 & 39 \\
$>70$ & 66 & 61 \\
\hline CCE - Clear cell ependymoma; AE - Anaplastic ependymoma; \\
ICP - Intracranial pressure
\end{tabular}

Comparison of Patient demographics, Presenting Symptoms and Kamofsky Performance Score

While most of the CCE tumors were supratentorial in location, AE was found to be equally distributed in supratentorial and infratentorial locations. Within CCE, the parietal lobe was the most common location, followed by temporoparietal lobe. Although temporoparietal lobe was the most occupied site by $\mathrm{AE}$, they were also distributed in occipital, cerebellar, and intraventricular regions.

When looking at T1-weighted images on MRI, we found that both CCE and AE showed hypointense signals. While on T2-weighted images on MRI, all the cases of CCE showed hyperintense signals, whereas $80 \%$ of the AE showed hyperintense signals, alongside $13 \%$ showing up as iso-hyperintense. These results are summarized in Table 2.

Table 2 
Prognostic Implications of Histological Clear Cells in High-Grade Intracranial Ependymal Tumors: A Retrospective Analysis from a Tertiar...

\begin{tabular}{|c|c|c|}
\hline & $\mathrm{CCE}$ & $\mathbf{A E}$ \\
\hline \multicolumn{3}{|l|}{ Tumor location (\%) } \\
\hline Supratentorial & $7 / 9(77)$ & $11 / 23(48)$ \\
\hline Infratentorial & $2 / 9(22)$ & $12 / 23(52)$ \\
\hline \multicolumn{3}{|l|}{ Distribution $(n)$} \\
\hline Parietal & 4 & - \\
\hline Temporoparietal & 2 & 6 \\
\hline Occipital & 1 & 4 \\
\hline Cerebellum & - & 4 \\
\hline Intraventricular & 1 & 3 \\
\hline Temporal & - & 3 \\
\hline Frontal & - & 2 \\
\hline Corpus callosum & 1 & - \\
\hline $\mathrm{CP}$ angle & - & 1 \\
\hline \multicolumn{3}{|l|}{ T1-weighted MRI (\%) } \\
\hline Hypo-intense & 67 & 61 \\
\hline Hypo-iso-intense & - & 8.7 \\
\hline Iso-intense & 11 & 8.7 \\
\hline Iso-hyper-intense & - & 4.3 \\
\hline Hyper-intense & 22 & 13 \\
\hline \multicolumn{3}{|l|}{ T2-weighted MRI (\%) } \\
\hline Hypo-intense & - & 3.5 \\
\hline Hypo-iso-intense & - & 3.5 \\
\hline Iso-hyper-intense & - & 13 \\
\hline Hyperintense & 100 & 80 \\
\hline \multicolumn{3}{|l|}{ MRI features (\%) } \\
\hline Cystic & 89 & 68 \\
\hline Solid & 45 & 45 \\
\hline Hemorrhagic & 22 & 9.1 \\
\hline Necrosis & 33 & 22 \\
\hline Contrast enhancement & 90 & 91 \\
\hline
\end{tabular}

CCE - Clear cell ependymoma; AE - Anaplastic ependymoma;

MRI - Magnetic resonance imaging

Open in a separate window

Comparison of Tumor Location, Distribution and MRI Features

The National Comprehensive Cancer Network USA clinical practice guidelines in oncology for the treatment of adult intracranial ependymoma were followed,[17] which include GTR whenever possible, followed by MRI spine for metastasis to cauda equina if histopathology was suggestive of AE Grade 3, followed by external beam radiation therapy (EBRT) 54-59.4 Gy, in 1.8-2.0 Gy fractions. In case of recurrence, reresection was performed if resectable followed by EBRT if no prior RXT was given. In case if prior RXT was given, then consideration was given to reirradiation or CMT. In our series, GTR could be achieved in $5(55 \%)$ cases of CCE and $6(26 \%)$ cases of AE while STR was done in $4(44 \%)$ 
cases of CCE and $15(65 \%)$ cases of AE. A biopsy was performed in two cases of AE. Postsurgical adjuvant therapy with RXT was given to $5(55 \%)$ cases of CCE and $12(52 \%)$ cases of AE, while CMT (temozolomide) alongside RXT was given to $3(33 \%)$ cases of CCE and $5(22 \%)$ cases of AE. One CCE patient refused further treatment, while 6 patients of AE were lost to follow-up. Recurrence occurred in 77\% (7/9) of CCE and 70\% (12/17) of AE. Repeat surgery was performed in 3 out of 7 patients with CCE as compared to 8 out of 12 patients with AE. Metastasis was present in $5(29 \%)$ cases of AE, whereas in only one patient with CCE.

Histopathological slides of both groups with specific characteristics are highlighted in Figure 1.

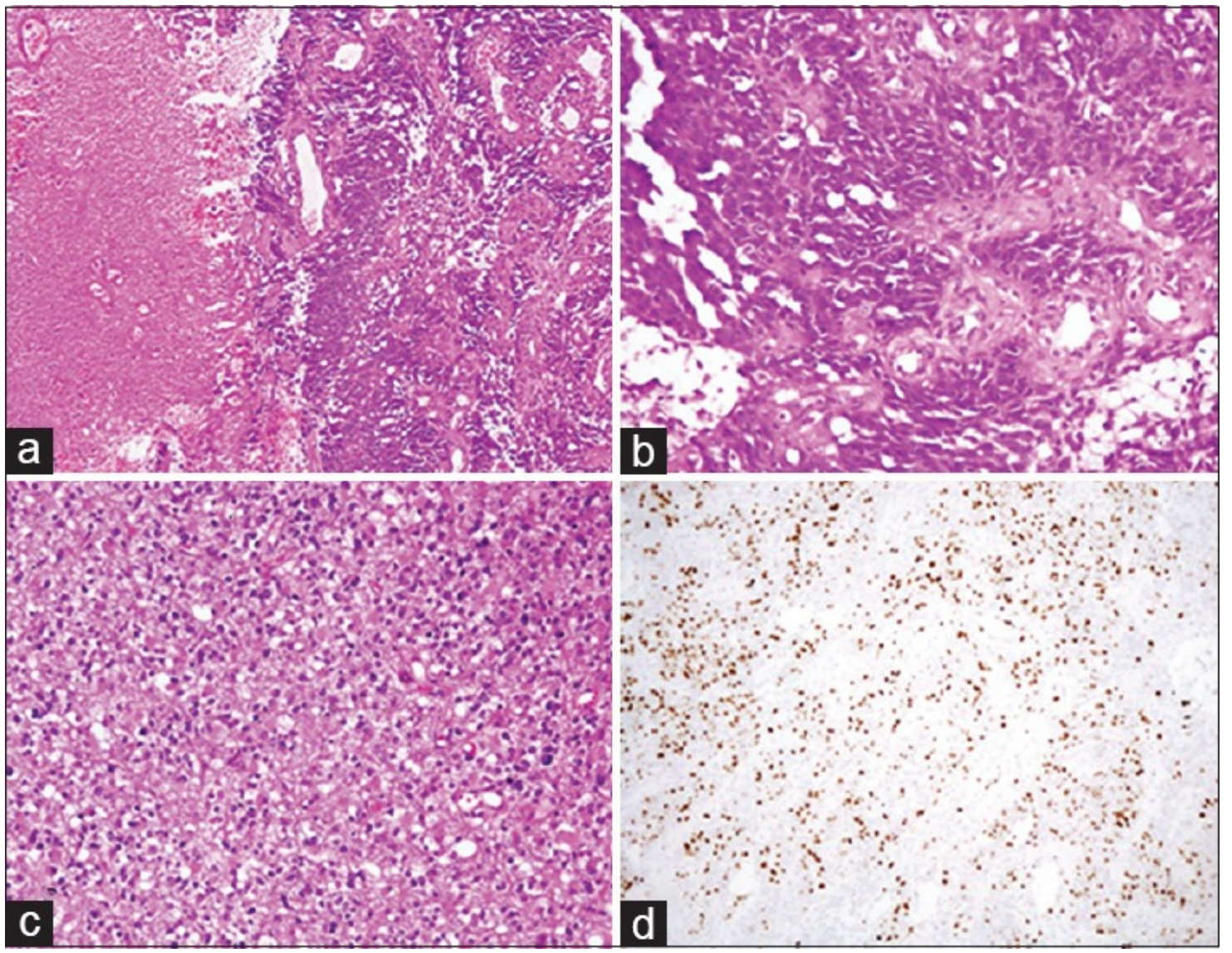

\section{Figure 1}

Histopathological slides of the tumors. (a) Anaplastic ependymoma in low magnification showing perivascular pseudorosettes and true rosettes, alongside necrosis. (b) Anaplastic cells showing high mitotic activity. (c) Clear cell ependymoma showing perivascular pseudorosettes - there is oligodendroglioma like clear cell ependymoma. (d) Glial fibrillary acidic protein staining in anaplastic ependymoma, with Ki-67 showing high proliferative index

The PFS for CCE was 9 months, ranging between 3 and 28 months, while 14 months for AE, ranging between 15 days and 60 months. The OS was 13 months for CCE, ranging between 3 and 41 months, while 18 months for AE, ranging between 1 and 60 months. Survival analysis with respect to age was statistically significant $(P<0.05)$ for CCE patients who were younger had better survival as compared to patients who were older than 55 years. Similarly in AE, although the pediatric cases were censored, 
statistical significance $(P<0.017)$ revealed that younger patients had a better prognosis as compared to the older patients [피마re 2].
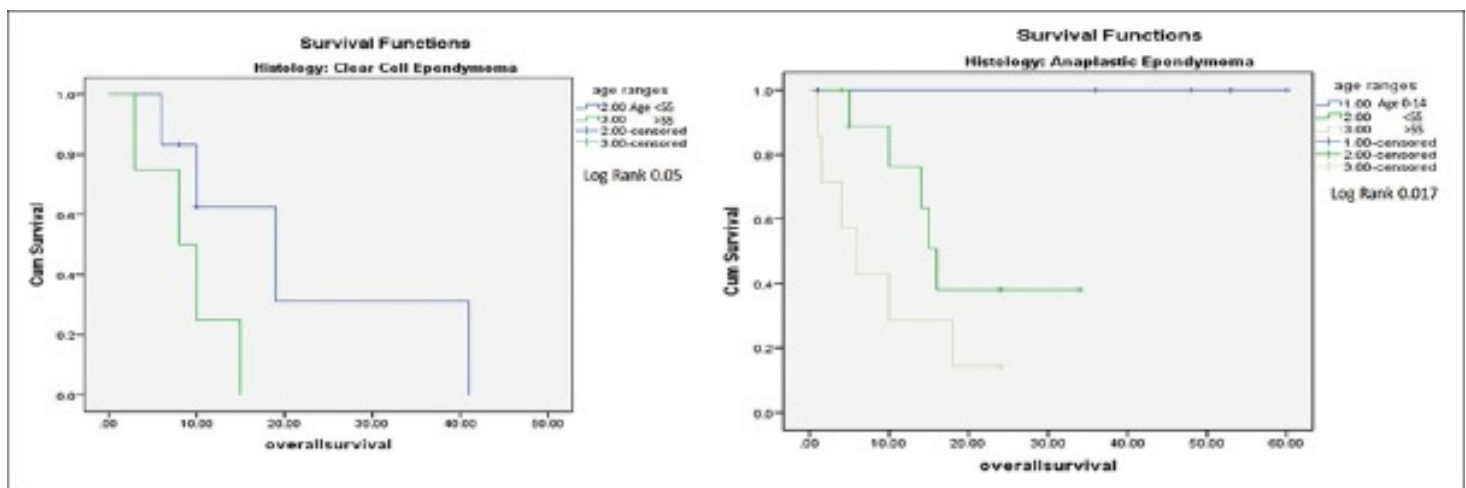

\section{Figure 2}

\section{Survival with respect to age}

Survival with respect to the extent of resection was not statistically significant $(P=0.14)$; however, it showed GTR had a better prognosis [Figure 3a]. Survival analysis of the two histopathologies showed that CCE had a 1.86 times worse prognosis than AE [igure 3b]. Survival with respect to recurrence was statistically significant $(P<0.03)$ highlighting that patients who had recurrence had a worse prognosis [ig $\underline{\text { Fre 4a] }}$, while survival with respect to postresection RXT for AE was significant $(P<$ 0.05 ) showing that patients who underwent RXT had a better prognosis, whereas in patients with CCE it was not significant $(P=0.1)$ [ $\underline{\text { Figure } 4 \mathrm{~b}}$ ].
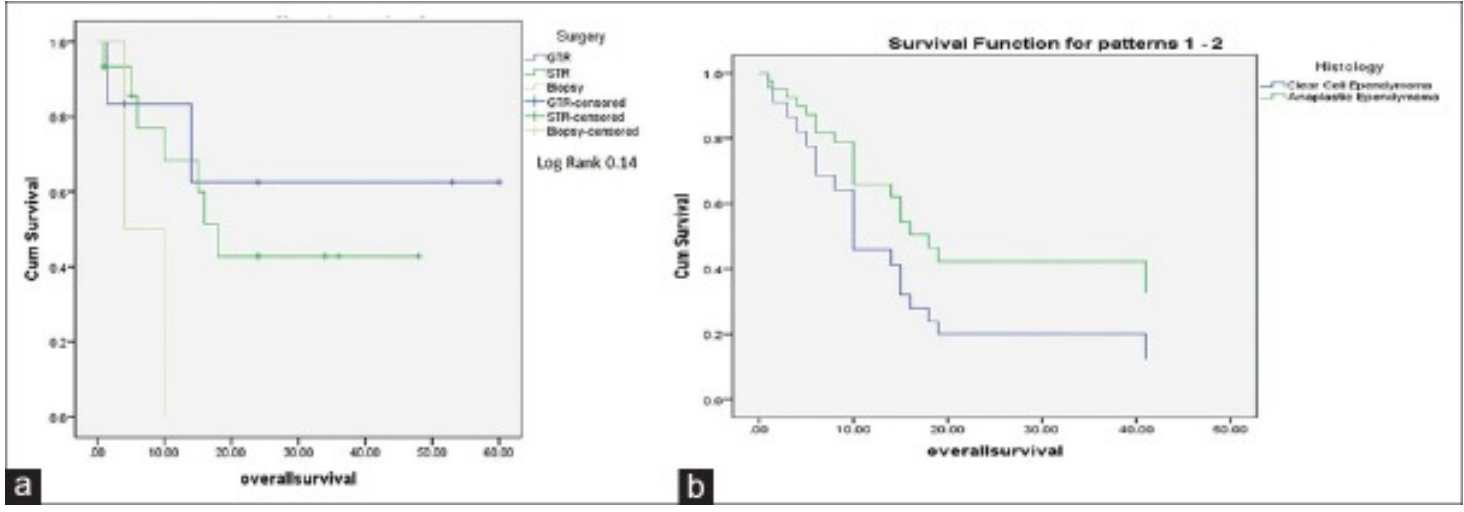

Figure 3

Survival analysis with respect to (a) extent of resection and (b) histopathology 


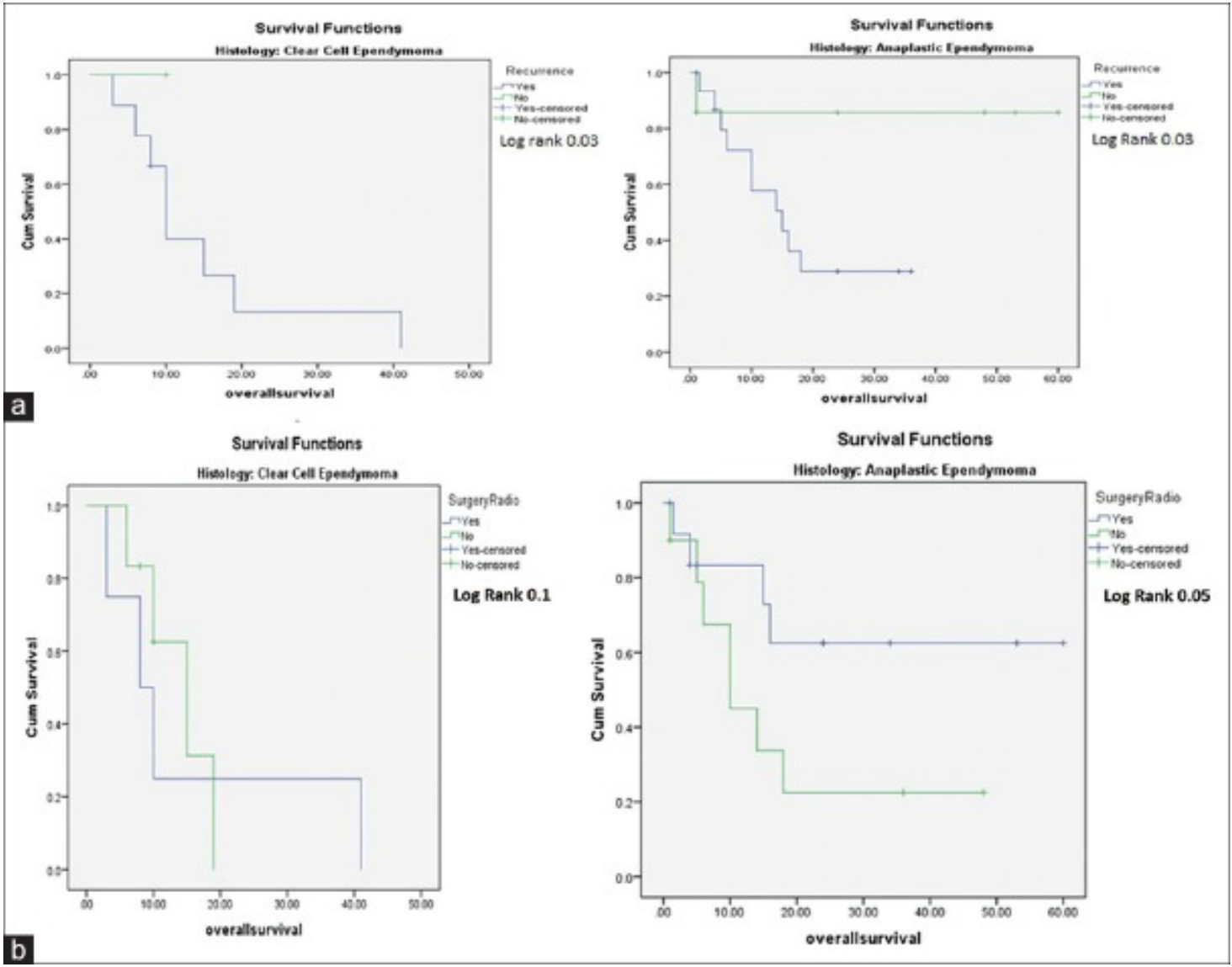

Figure 4

Survival analysis with respect to (a) recurrence and (b) radiotherapy

\section{Discussion}

CCE is designated as Grade 2 ependymal tumor, having a predilection for the supratentorial compartment, occurring predominantly in young patients.[18] In contrast to the WHO classification designating CCE as Grade 2, we have 9 out of 32 cases demonstrating the ependymal clear cells in AE Grade 3 instead of ependymoma Grade 2 - also, previously highlighted in the literature.

$[\underline{10}, \underline{19}, \underline{20}, \underline{21}, \underline{22}, \underline{23}]$

The median age of our series for CCE was 49 years (age range 24-72 years) and for AE was 37 years (age range 3 months -75 years). We found comparable cohorts with similarity to our age group, reported by Kawano et al.,[7] Min and Scheithauer[24] and in a few other case reports.[ㅁ, $\underline{15}, \underline{25}, \underline{26}]$ However, the two biggest cohorts on the subject were conducted by Fouladi et al.[10] and Rickert et $a l .,[\underline{23}]$ who have reported their work in pediatric age group, alongside others.[ㄹ2, 27, 28] The male predominance as previously reported was also supported by our series for CCE with a male-female ratio of 2:1, but for $\mathrm{AE}$, a female shift was observed.

The clinical presentation of our groups was more or less similar with a slight predominance of features of raised ICP and dizziness being reported more so in AE patients as compared to CCE patients, who followed the clinical trend previously reported in studies.[10,24] The primary tumor site highlighted in literature was supratentorial[10,24] although occasional occurrence at other sites including cerebellum, medulla oblongata, and fourth ventricle have also been described.[ㅍ, $\underline{9}, \underline{11}]$ Our study complimented 
with similar results, especially in CCE group, however, in the AE patients, we found equal distribution in supratentorial and infratentorial locations.

Radiologically, Fouladi et al.[10] demonstrated most cases to be isointense on both T1- and T2weighted images, while Hayashi et al.[27] showed hypo- to iso-intense on T1 and hyperintense on T2weighted images of MRI. In our study, both CCA and AE showed hypointense signal on T1, while on T2-weighted images, all cases of CCE showed hyperintense signals, but only $80 \%$ of AE showed hyperintense signals with $13 \%$ accounting for iso- to hyper-intense signals. Associated enhancement, calcification, necrosis, cystic areas, and mass effect have also been reported.[ㄱ, $\underline{10}, \underline{15}, \underline{24}, \underline{27}]$ In our study, both CCE and AE showed enhancement in 90\% cases, with necrosis and hemorrhage more pronounced in CCE with $33 \%$ and $22 \%$, respectively, as compared to $22 \%$ and $9 \%$, respectively for AE. The cystic component was slightly more prevalent in CCE patients than AE patients while both had equal distribution with respect to solid areas.

With no defined WHO criteria, histological features of CCE varies from focal to diffuse,[10,23] alongside a description of perivascular pseudorosettes with the absence of true rosettes, and ependymal canals being reported.[6,11] In addition, the presence of oligodendroglioma (ODG) like clear cells being present in AE Grade 3 rather than ependymoma Grade 2 has been extensively reported. $[\underline{10}, \underline{19}, \underline{20}, \underline{21}, \underline{22}, \underline{23}, \underline{29}]$ MIB 1 (ki-67) index has been described the pertinent prognostic factor for defining anaplasia in ependymoma.[리 ] These findings were consistent with our series.

The median PFS of our study was 9 and 14 months postsurgery for CCE and AE, respectively, while median OS postsurgery was 13 months for CCE and 18 months for AE. These results were statistically different from the ones previously reported. Armstrong et al.[31] reported a PFS and OS of 18 months and 67 months, respectively, for adult Grade 3 ependymal tumors. For CCE, Rickert et al.[23] reported a mean survival of $>52$ months and Fouladi et al.[10] A 5-year PFS was 34\% $\pm 20 \%$ and OS $75 \% \pm$ $19 \%$. None of our patients survived post 5 years. To our comparison are two case series. Foremost, reported for the first time from Pakistan, in our previous work on ependymal tumors with ODG like clear cells,[29] we demonstrated a median PFS and OS of 8 and 10 months, respectively and second, Jain et al.[20] from India reported three cases with one patient lost to follow-up at 4 months and the other two dying of disease at 21 and 24 months, respectively. Thus, suggesting a more aggressive nature of the tumor in this part of the world - Pakistan and India.

Among the patient-related prognostic factors that we identified, age $<55$ years had a positive impact on survival analysis in both CCE and AE - being consistent with those already reported.[32,33] The extent of surgery has been reported as one of the most significant predictors of outcome for intracranial ependymomas, $[\underline{4}, \underline{32}]$ with GTR being significantly associated with better PFS and OS.[푸] Survival with respect to the extent of resection was not significant for our series; however, GTR did show a better prognosis. In addition, recurrence was associated with a worse prognosis, with metastasis accounting for $29 \%$ of AE patients but only one patient of CCE. Postoperative irradiation has been reported to significantly improve local control, $[\underline{34}, \underline{35}]$ with Rogers et al.[34] recommending the use of postoperative RXT regardless of the extent of surgical resection. Our series highlighted better prognosis with RXT in patients with AE, with no meaningful significance for patients with CCE. Survival analysis of the two histopathologies highlighted the presence of clear cells in intracranial high-grade ependymal tumors being 1.8 times more hazardous on OS.

Our limitation was a small sample size owing to the rare presentation of this tumor, a retrospective study design, a single institution data, involvement to multiple neurosurgeons performing surgeries over this period and loss to follow-up of six patients. 
Clear Cells in Grade 3 ependymal tumors are found mainly in an adult population, with a predilection for supratentorial parietal location. We observed worse progression-free and OS in the presence of clear cells in comparison with classic AE. On univariate and multivariate analysis, age $>55$ years and recurrence of disease were statistically significant factors for poor OS, with clear cells having a hazard ratio of 1.8 times more on OS. The presence of disease in this part of the world - Pakistan and India may follow a more aggressive course.

\section{Financial support and sponsorship}

Nil.

\section{Conflicts of interests}

There are no conflicts of interest.

\section{References}

1. Dützmann S, Schatlo B, Lobrinus A, Murek M, Wostrack M, Weiss C, et al. A multi-center retrospective analysis of treatment effects and quality of life in adult patients with cranial ependymomas. J Neurooncol. 2013;114:319-27. [PubMed]

2. Fuller GN, Scheithauer BW. The 2007 revised World Health Organization (WHO) classification of tumours of the central nervous system: Newly codified entities. Brain Pathol. 2007;17:304-7. [PubMed]

3. Perilongo G, Massimino M, Sotti G, Belfontali T, Masiero L, Rigobello L, et al. Analyses of prognostic factors in a retrospective review of 92 children with ependymoma: Italian Pediatric Neurooncology Group. Med Pediatr Oncol. 1997;29:79-85. [ubMed]

4. Paulino AC, Wen BC, Buatti JM, Hussey DH, Zhen WK, Mayr NA, et al. Intracranial ependymomas: An analysis of prognostic factors and patterns of failure. Am J Clin Oncol. 2002;25:117-22. [PubMed]

5. Sala F, Talacchi A, Mazza C, Prisco R, Ghimenton C, Bricolo A. Prognostic factors in childhood intracranial ependymomas: The role of age and tumor location. Pediatr Neurosurg. 1998;28:135-42. [PubMed]

6. Kleihues P, Burger PC, Scheithauer BW. The new WHO classification of brain tumours. Brain Pathol. 1993;3:255-68. [ubMed]

7. Kawano N, Yada K, Aihara M, Yagishita S. Oligodendroglioma-like cells (clear cells) in ependymoma. Acta Neuropathol. 1983;62:141-4. [릴ed]

8. Akutsu H, Shibata Y, Okazaki M, Hyodo A, Matsumura A. Intramedullary clear cell ependymoma in the cervical spinal cord: Case report. Neurosurgery. 2000;47:1434-7. [PubMed]

9. Amatya VJ, Takeshima Y, Kaneko M, Nakano T, Yamaguchi S, Sugiyama K, et al. Case of clear cell ependymoma of medulla oblongata: Clinicopathological and immunohistochemical study with literature review. Pathol Int. 2003;53:297-302. [PubMed]

10. Fouladi M, Helton K, Dalton J, Gilger E, Gajjar A, Merchant T, et al. Clear cell ependymoma: A clinicopathologic and radiographic analysis of 10 patients. Cancer. 2003;98:2232-44. [ubMed]

11. Katoh M, Satoh T, Nishiya M, Murata J, Ishii N, Saitoh H, et al. Clear cell ependymoma of the fourth ventricle. Neuropathology. 2004;24:330-5. [PubMed] 
12. Kawano N, Yada K, Yagishita S. Clear cell ependymoma. A histological variant with diagnostic implications. Virchows Arch A Pathol Anat Histopathol. 1989;415:467-72. [PubMed]

13. Kim YJ, Tsunoda S, Yokoyama K, Miyamoto K, Tamai M, Yamauchi M. Clear cell ependymoma with a lipidized component that developed in the thoracic spinal cord. Neurol Res. 2003;25:324-8. [PubMed]

14. Packer RR, Schiff D. Neuro-oncology. New Jersey, USA: John Wiley and Sons; 2012.

15. Sato Y, Ochiai H, Yamakawa Y, Nabeshima K, Asada Y, Hayashi T. Brain surface ependymoma. Neuropathology. 2000;20:315-8. [PubMed]

16. Gupta K, Salunke P. Understanding ependymoma oncogenesis: An update on recent molecular advances and current perspectives. Mol Neurobiol. 2017;54:15-21. [PubMed]

17. Nabors LB, Ammirati M, Bierman PJ, Brem H, Butowski N, Chamberlain MC, et al. Central nervous system cancers. J Natl Compr Canc Netw. 2013;11:1114-51. [MC free article] [PubMed]

18. Teo C, Nakaji P, Symons P, Tobias V, Cohn R, Smee R. Ependymoma. Childs Nerv Syst. 2003;19:270-85. [PubMed]

19. Deb P, Manu V, Pradeep H, Bhatoe HS. Intraparenchymal clear cell ependymoma. J Cytol. 2011;28:73-6. [PMC free article] [PubMed]

20. Jain D, Sharma MC, Arora R, Sarkar C, Suri V. Clear cell ependymoma: A mimicker of oligodendroglioma - Report of three cases. Neuropathology. 2008;28:366-71. [PubMed]

21. Lee BH, Kwon JT, Park YS. Supratentorial clear cell ependymoma mimicking oligodendroglioma: Case report and review of the literature. J Korean Neurosurg Soc. 2011;50:240-3. [PMC free article] [PubMed]

22. Payet M, Conter C, Labrousse F, De Paula AM, Marabelle A, Branger DF, et al. Clear cell ependymoma with trisomy 19 developing bone metastases. Childs Nerv Syst. 2012;28:739-42. [PubMed]

23. Rickert $\mathrm{CH}$, Korshunov A, Paulus W. Chromosomal imbalances in clear cell ependymomas. Mod Pathol. 2006;19:958-62. [릴ed]

24. Min KW, Scheithauer BW. Clear cell ependymoma: A mimic of oligodendroglioma: Clinicopathologic and ultrastructural considerations. Am J Surg Pathol. 1997;21:820-6. [PubMed] 25. Cenacchi G, Giangaspero F, Cerasoli S, Manetto V, Martinelli GN. Ultrastructural characterization of oligodendroglial-like cells in central nervous system tumors. Ultrastruct Pathol. 1996;20:537-47. [PubMed]

26. Suh JH, Hong SM, Lee IC. Clear cell ependymoma. Korean J Pathol. 1997;31:383-7.

27. Hayashi K, Tamura M, Shimozuru T, Kasamo S, Hirahara K, Kadota K, et al. Extra-axial ependymoma - Case report. Neurol Med Chir (Tokyo) 1994;34:295-9. [PubMed]

28. Parafeynikov V, Boaz JC, Bonnin JM. Clear-cell ependymoma: A report of intracortical tumor with significant desmoplasia. Neuropathology. 2008;28:165-70. [PubMed]

29. Hashmi FA, Khan MF, Khan SA, Waqas M, Bari ME, Ahmed A. Ependymal tumors with oligodendroglioma like clear cells: Experience from a tertiary care hospital in Pakistan. Surg Neurol Int. 2015;6(Suppl 23):S583-9. [PMC free article] [PubMed] 
30. Kurt E, Zheng PP, Hop WC, van der Weiden M, Bol M, van den Bent MJ, et al. Identification of relevant prognostic histopathologic features in 69 intracranial ependymomas, excluding myxopapillary ependymomas and subependymomas. Cancer. 2006;106:388-95. [PubMed]

31. Armstrong TS, Vera-Bolanos E, Bekele BN, Aldape K, Gilbert MR. Adult ependymal tumors: Prognosis and the M. D. Anderson Cancer Center experience. Neuro Oncol. 2010;12:862-70. [PMC free article] [PubMed]

32. Reni M, Brandes AA, Vavassori V, Cavallo G, Casagrande F, Vastola F, et al. A multicenter study of the prognosis and treatment of adult brain ependymal tumors. Cancer. 2004;100:1221-9. [PubMed]

33. Metellus P, Figarella-Branger D, Guyotat J, Barrie M, Giorgi R, Jouvet A, et al. Supratentorial ependymomas: Prognostic factors and outcome analysis in a retrospective series of 46 adult patients. Cancer. 2008;113:175-85. [PubMed]

34. Rogers L, Pueschel J, Spetzler R, Shapiro W, Coons S, Thomas T, et al. Is gross-total resection sufficient treatment for posterior fossa ependymomas? J Neurosurg. 2005;102:629-36. [ubMed]

35. McLaughlin MP, Marcus RB, Jr, Buatti JM, McCollough WM, Mickle JP, Kedar A, et al. Ependymoma: Results, prognostic factors and treatment recommendations. Int J Radiat Oncol Biol Phys. 1998;40:845-50. [PubMed]

Articles from Asian Journal of Neurosurgery are provided here courtesy of Wolters Kluwer -- Medknow

\section{Publications}

